\title{
Does Outcome Reporting Bias "Cause" Cancer? Risks Associated with Hidden Data on Angiotensin Receptor Blockers
}

\author{
Gregory Egan, Jana Lee, Rajwant Minhas, and Aaron M Tejani
}

\begin{abstract}
Conflicting reports have been published regarding the influence of angiotensin receptor blockers (ARBs) on the incidence of cancer. One meta-analysis reported a $1 \%$ absolute increase in the incidence of cancer associated with ARBs over 4 years. Contrasting findings were reported in an industry-sponsored meta-analysis and in another meta-analysis, both of which showed no difference in the incidence of cancer in ARB treatment groups relative to control groups. The US Food and Drug Administration has recently asserted that evidence does not support an association between ARBs and the development of cancer. The current review compares the 3 published meta-analyses assessing the association between ARBs and cancer and shows that outcome reporting bias contributed to the conflicting results. Given the prevalence of this form of bias in the scientific literature, the processes for systematic reviews and meta-analyses are under siege, and there is an important role for health care regulators to play. If all outcome data from clinical trials were to be reported in the public domain, independent analyses could be performed and the results of industry-sponsored trials verified. Furthermore, if regulators were to mandate the publication, in the public domain, of all clinical outcomes collected in clinical trials, outcome reporting bias could be eliminated.
\end{abstract}

Key words: outcome reporting bias, meta-analysis, angiotensin receptor blockers

Can J Hosp Pharm 2012;65(5):387-393

\section{RÉSUMÉ}

Contexte : Des rapports contradictoires ont été publiés quant à l'influence des antagonistes des récepteurs de l'angiotensine (ARA) sur l'incidence du cancer. Une méta-analyse a signalé une augmentation absolue de $1 \%$ de l'incidence du cancer associée aux ARA sur une période de quatre ans. Des résultats très différents issus de deux méta-analyses, dont l'une a été commanditée par l'industrie, n'ont montré aucune différence dans l'incidence du cancer dans les groupes traités par les ARA comparativement aux groupes témoins. La Food and Drug Administration des États-Unis a déjà affirmé que les données probantes ne corroborent pas le lien entre les ARA et l'apparition de cancer. La présente analyse compare les trois méta-analyses publiées évaluant le lien entre les ARA et le cancer, et montre que les biais de publication des résultats ont contribué à ces conclusions contradictoires. Étant donné la prévalence de cette forme de biais dans la littérature scientifique, la démarche entourant les analyses systématiques et les méta-analyses est sur la sellette et les organismes de réglementation des soins de santé ont un important rôle à jouer dans ce contexte. Si toutes les données issues des études cliniques étaient rendues publiques, des analyses indépendantes pourraient être effectuées et les résultats des études commanditées par l'industrie pourraient être vérifiés. En outre, si les organismes de réglementation exigeaient de rendre publiques l'ensemble des données issues des études cliniques, on pourrait alors éliminer les biais de publication des résultats.

Mots clés : biais de publication des résultats, méta-analyse, antagonistes des récepteurs de l'angiotensine

[Traduction par l'éditeur] 


\section{INTRODUCTION}

W ithin the past couple of years, several publications have reached conflicting conclusions as to whether angiotensin receptor blockers (ARBs) increase the incidence of cancer. The first indication that these drugs may have this effect was an incidental finding of the CHARM trial, a randomized controlled trial (RCT) comparing candesartan and placebo in the treatment of heart failure, published in 2003. ${ }^{1}$ The CHARM Investigators found greater cancer mortality in the ARB treatment group: 86 (2.3\%) versus 59 (1.6\%) (odds ratio [OR] 1.45, 95\% confidence interval [CI] 1.04-2.02). ${ }^{1}$

Subsequently, 3 meta-analyses have been published pooling different combinations of outcome data (see publication timeline in Figure 1). In June 2010, Sipahi and others ${ }^{2}$ published a meta-analysis of 5 trials, with a total of 61590 patients, implicating $A R B s$ as a class associated with an increased incidence of cancer (OR 1.08, 95\% CI 1.01-1.15) over an average 4-year follow-up. In April 2011, another metaanalysis, covering 15 trials with a total of 134000 patients and published by the ARB Trialists Collaboration (ATC), reported no statistically significant difference in the incidence of cancer in the ARB treatment group (OR 1.00, 95\% CI 0.95-1.04). ${ }^{3}$ Earlier that year, in January 2011, Bangalore and others ${ }^{4}$ published an analysis of the risk of cancer associated with all antihypertensive drug classes. That analysis included 14 RCTs

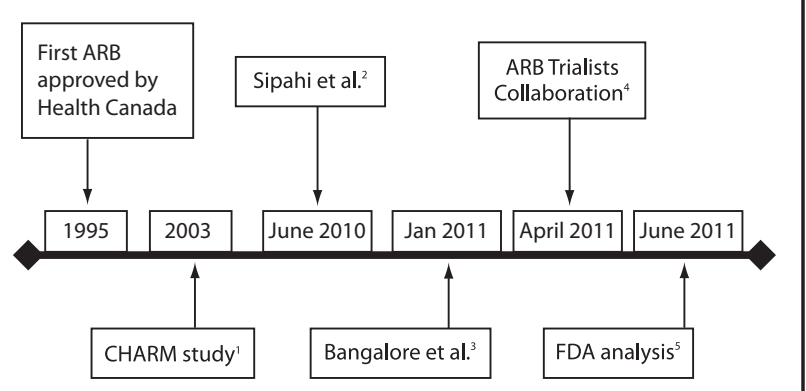

Figure 1. Timeline for publication of meta-analyses of cancer risk associated with angiotensin receptor blockers (ARBS). FDA = US Food and Drug Administration. with a total of 99775 patients and concluded that there was no increased risk of cancer in the ARB treatment group (OR 0.98, 95\% CI 0.93-1.03). In June 2011, the US Food and Drug Administration (FDA) published its own in-house metaanalysis, which encompassed 31 trials and more than 155000 patients, the largest yet. The FDA analysis eliminated ARBs as a factor increasing the risk of cancer (relative risk $0.99,95 \% \mathrm{CI}$ 0.92-1.06).5 This array of contradictory evidence prompted the current investigation into the differences among these meta-analyses.

The underlying physiologic mechanism by which ARBs may increase the incidence of cancer has been described from in vitro investigations. There are 2 types of angiotensin receptors, type 1 (AT1R) and type 2 (AT2R). The AT1Rs are located in the kidney, heart, brain, vascular smooth muscle cells, placenta, platelets, and fat cells, whereas the AT2Rs are important in fetal development, although their function is not well understood. ${ }^{6.7}$ In vitro studies have shown that agonism at both of the angiotensin receptor subtypes (AT1R and AT2R) is involved in the regulation of cellular proliferation, angiogenesis, and tumour progression. ${ }^{6,8-10}$ ARBs exert their clinical effect through ATR1 antagonism, and it is postulated that they may have anti-angiogenic properties, thereby suppressing tumour growth. ${ }^{8}$ However, studies have shown that despite AT1R inhibition, tumour progression can still occur. ${ }^{8}$ There is also evidence from animal models that unopposed AT2R stimulation (when AT1Rs are blocked by ARBs) can lead to tumour progression. ${ }^{7}$ Although this has yet to be shown in humans, tumour progression caused by AT2R stimulation is the proposed mechanism for the increased incidence of cancer within ARB treatment groups in clinical trials. ${ }^{7-9}$

ARBs are commonly prescribed inhibitors of the renin-angiotensin-aldosterone system and are the alternative to angiotensin-converting enzyme (ACE) inhibitors in cases of allergy or intolerance. ${ }^{11}$ Indications for ARBs approved by Health Canada are hypertension, heart failure, diabetic nephropathy, and secondary prevention of cardiovascular events. ${ }^{12}$ Generally, ARBs have no mortality benefit over placebo for these indications (Table 1). More specifically, ARBs have no mortality benefit for hypertension, ${ }^{13,14}$ diabetic

Table 1. Clinical Benefit of Angiotensin Receptor Blockers (ARBs) for Approved Indications

\begin{tabular}{lcc} 
& \multicolumn{2}{c}{ Mortality Benefit: OR (95\% Cl) } \\
\cline { 2 - 3 } Indication for ARB & $\begin{array}{c}\text { ACE Inhibitor } \\
\text { Versus ARB }\end{array}$ & $\begin{array}{c}\text { ARB Versus } \\
\text { Placebo }\end{array}$ \\
\hline Hypertension & $0.96(0.87-1.06)$ & $0.96(0.88-1.06)$ \\
Heart failure & $0.94(0.81-1.07)$ & $0.83(0.69-1.00)$ \\
Secondary prevention of cardiovascular events & $0.97(0.90-1.04]$ & No benefit \\
Nephropathy (urine albumin $>30 \mathrm{~g} / \mathrm{L})$ & $0.79(0.63-0.99)$ & $0.99(0.85-1.17)$ \\
\hline ACE = angiotensin-converting enzyme, Cl = confidence interval, OR = odds ratio.
\end{tabular}


nephropathy, ${ }^{15}$ or secondary prevention of cardiovascular events. ${ }^{16}$ A meta-analysis published in 2008 compared ARBs with ACE inhibitors or control in terms of mortality associated with heart failure and found no statistical difference. ${ }^{17}$ However, a $17 \%$ reduction in hospital admissions, relative to placebo, was observed with the use of ARBs. ${ }^{17,18}$

The current review had 3 specific objectives: to elucidate the reasons for conflicting data on the outcome of cancer incidence between the 3 meta-analyses, to understand the impact of outcome reporting bias on meta-analysis of clinical trials, and to describe the role that health care regulators could play in minimizing the occurrence of reporting bias.

\section{COMPARISON OF 3 META-ANALYSES}

Sipahi and others ${ }^{2}$ set out to determine the effect of ARBs on the occurrence of new cancers. The authors were independent clinicians from the Harrington-McLaughlin Heart and Vascular Institute in Cleveland, Ohio. They performed a systematic search of all publicly available data from ARB trials reporting on cancer outcomes available from MEDLINE, Scopus, the Cochrane Central Register of Controlled Trials, the Cochrane Database of Systematic Reviews, and the FDA. The search, completed in November 2009, yielded 9 trials fitting the inclusion criteria (RCTs with ARB use in at least one treatment group, follow-up for more than 12 months, and enrolment of at least 100 patients). Five of these 9 trials (accounting for 61590 patients) reported on the incidence of cancer and were therefore included in the analysis of the primary outcome. Of these 5 trials, LIFE, TROPHY, and TRANSCEND had cancer as a prespecified end point, whereas ONTARGET and PROFESS reported cancer outcomes as a serious adverse event. (For a list of the trials included in the meta-analyses and mentioned in the current review, see Appendix 1, available at www.cjhp-online.ca/index.php/cjhp/issue/view/89/showToc.) After pooling the data from these trials, Sipahi and others ${ }^{2}$ found a statistically significant increase in the incidence of cancer among patients who had been treated with ARBs (Figure 2, top section). The ATC analysis also set out to determine the effect of ARBs on the occurrence of new cancers. ${ }^{3}$ The authors were the primary investigators of industry-sponsored ARB trials. In their meta-analysis, the search strategy was not explicitly described; rather, the authors simply stated that previously unpublished patient-level data had been obtained from the authors of the ARB trials. The ATC obtained cancer outcome data from the 15 major ARB trials that had been completed as of August 2010: ACTIVE-I, CHARM, DIRECT, I-PRESERVE, IDNT, LIFE, NAVIGATOR, ONTARGET, PROFESS, SCOPE, TRANSCEND, TROPHY, Val-HeFT, VALIANT, and VALUE. Data from 134914 $(97.1 \%)$ of the patients in these trials were pooled for analysis. The missing $2.9 \%$ of patients were those with known cancer at

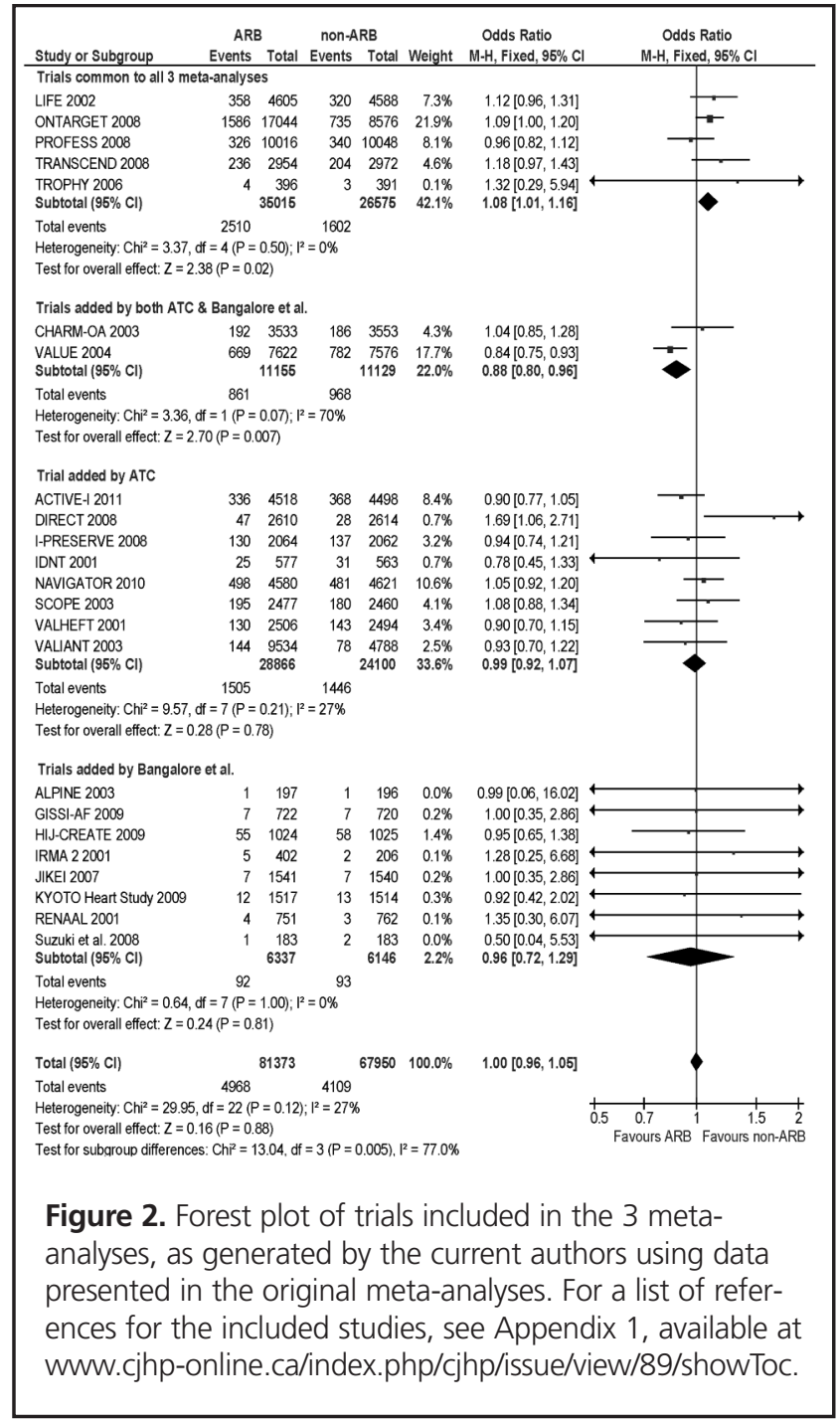

baseline (reported in the ONTARGET, TRANSCEND, VALIANT, and CHARM trials) and those for whom cancer outcomes were unknown. ${ }^{3}$ Ultimately, the ATC analysis showed no statistically significant difference in the incidence of cancer in the ARB treatment group (Table 2).

The objective of Bangalore and others ${ }^{4}$ was to assess the association of antihypertensive drug classes with the risk of cancer. The authors had perceived or actual conflicts of interest with several pharmaceutical companies that manufactured ARBs. ${ }^{4}$ Their search included PubMed, Embase, Cochrane Central Register of Controlled Trials, the grey literature, and the FDA database up to August 2010. They also searched the reference lists of included RCTs and review articles and contacted authors of RCTs for additional data as required. Their analysis included 14 RCTs, and they performed a meta-analysis of cancer risk using data for 99775 patients. They found no significant increase in the risk of cancer in the ARB treatment group (Table 2). 


\section{Table 2. Comparison of Odds Ratios for 3 Meta-analyses of ARB Trials}

\begin{tabular}{lc} 
Study & $\begin{array}{c}\text { OR }(95 \% \mathrm{Cl}) \text { for } \\
\text { Occurrence of Cancer }\end{array}$ \\
\hline${\text { Sipahi et al. }{ }^{2}}$ ARB Trialists Collaboration ${ }^{3}$ & $1.08(1.01-1.15)$ \\
Bangalore et al. $^{4}$ & $1.00(0.95-1.04)$ \\
ARB = angiotensin receptor blocker, $\mathrm{Cl}=$ confidence interval, \\
OR = odds ratio.
\end{tabular}

Comparison of the analyses by Sipahi and others ${ }^{2}$ and by the $\mathrm{ATC}^{3}$ reveals a striking difference in the raw numeric data for cancer outcomes from 5 trials that were included in both meta-analyses: LIFE, ONTARGET, PROFESS, TRANSCEND, and TROPHY. This difference was due to the exclusion from the ATC analysis ${ }^{3}$ of patients with known cancer at baseline. However, excluding those patients carries the risk of introducing bias into the result, as the treatment groups may be unbalanced (an effect that occurs when patients are removed from an analysis after randomization). Sound methodology would dictate that all patients randomized to a treatment group should be included in the outcome analysis, with imputed outcomes for missing patient data being considered at the opposite extremes (i.e., all patients experienced the outcome or no patients experienced the outcome). This intention-to-treat principle of analysis is a type of sensitivity analysis that mitigates the risk of bias, whereby a researcher must explore whether the imputation of missing patient data causes a change in the measured effect. ${ }^{19}$ However, despite the numeric differences in data for 5 of the trials included in these 2 meta-analyses, ${ }^{2,3}$ the measured effect of ARBs on cancer did not differ. This lack of difference in effect is demonstrated both by a sensitivity analysis conducted by Sipahi and others, ${ }^{2}$ whereby the meta-analysis was limited to patients without a history of cancer at baseline and all neoplasms reported in the CHARM trial were assumed to be malignant (OR 1.10, 95\% CI 1.02-1.18), and by pooling data from the ATC meta-analysis ${ }^{3}$ for the 5 overlapping trials with the data in the analysis of Sipahi and others ${ }^{2}$ (OR 1.07, 95\% CI 1.00-1.15) (Figure 3). It is evident that the conflicting results of these 2 meta-analyses ${ }^{2,3}$ were related to unpublished cancer outcome data from RCTs that were unique to the ATC analysis. ${ }^{3}$

The meta-analysis by Sipahi and others ${ }^{2}$ included all publicly available data up to November 2009. To minimize the impact of reporting bias, Sipahi and others ${ }^{2}$ contacted the authors of individual RCTs to obtain unpublished data on cancer outcomes, if not provided in the published manuscript. Specifically, Sipahi and others ${ }^{2}$ identified VALUE, VALIANT, Val-HeFT, and CHARM as large RCTs eligible for inclusion in their meta-analysis, but cancer incidence was not reported in the published reports of these RCTs. In correspondence with the authors of VALUE, the Sipahi team was told that cancer

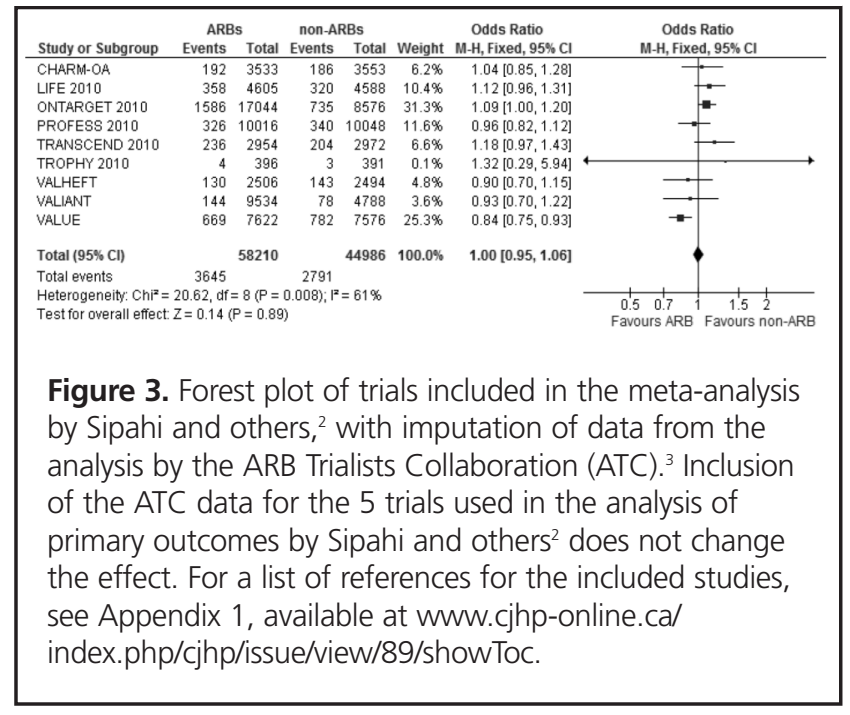

outcomes had not been recorded in that clinical trial (Ilke Sipahi, personal communication by email, September 2011). For VALIANT and Val-HeFT, only cancer-related mortality was reported in the final publications, and CHARM did not differentiate between benign and malignant neoplasms when reporting outcomes. ${ }^{1-3}$ Therefore, none of these trials were included in the primary outcome of the meta-analysis by Sipahi and others. ${ }^{2}$ However, for the ATC analysis, ${ }^{3}$ the incidence of cancer for all of these trials (VALUE, VALIANT, Val-HeFT, and (HARM) was made available and was included in the pooled analysis. The pooling of cancer data from these 4 trials with data from the 5 trials analyzed by Sipahi and others ${ }^{2}$ (LIFE, ONTARGET, PROFESS, TRANSCEND, and TROPHY) negates the measured effect: OR 1.00, 95\% CI 0.95-1.06 (Figure 4).

The meta-analyses of Sipahi and others ${ }^{2}$ and Bangalore and others ${ }^{4}$ had some similarities but also some differences. For new cancer occurrence, they analyzed the same outcome data for the trials they had in common. However, data from 9 RCTs

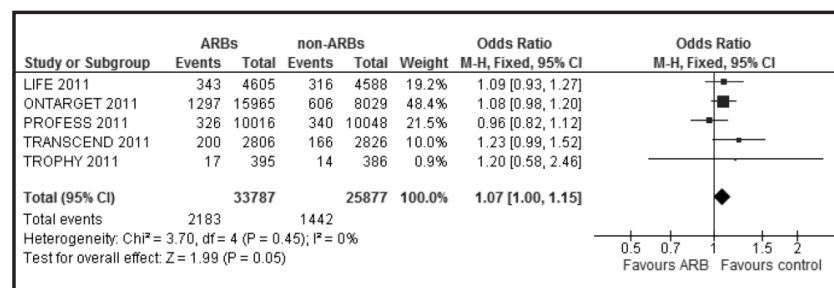

Figure 4. Forest plot with addition of trials identified by Sipahi and others ${ }^{2}$ but not included because of reporting bias. Data for the VALUE, Val-HeFT, VALIANT, and CHARM trials were obtained from data tables in the ATC meta-analysis. ${ }^{3}$ For a list of references for the included studies, see Appendix 1, available at www. cjhp-online.ca/index.php/cjhp/issue/view/89/showToc. 
included in the study by Bangalore and others ${ }^{4}$ were not included by Sipahi and others. ${ }^{2}$ More specifically, 4 unpublished trials (ALPINE, HIJ-CREATE, IRMA-2, and KYOTO) were identified by Bangalore and others ${ }^{4}$ but not by Sipahi and others. ${ }^{2}$ Five additional trials (GISSI-AF, JIKEI, RENAAL, Suzuki et al., and VALUE) were published, but did not include cancer outcome data. Bangalore and others ${ }^{4}$ contacted the authors of these trials to obtain additional data on cancer outcomes. It is not clear if the Sipahi team was unsuccessful in attempts to find these data. We contacted Sipahi (in June 2012) to determine the reason why these trials were not included in their analysis, but had not received a response by the time the current review was published (autumn 2012). Adding the 9 trials identified by Bangalore and others ${ }^{4}$ to the 5 trials identified by Sipahi and others ${ }^{2}$ negates the increased incidence of cancer in the ARB treatment group (OR 0.98, 95\% CI 0.93-1.03).

The ATC analysis ${ }^{3}$ included 7 RCTs that were not included by Bangalore and others. ${ }^{4}$ Two of these trials, DIRECT and SCOPE, were identified by Bangalore and others, who tried to contact the authors of the original studies for additional data but received no response. Two other trials, I-PRESERVE and IDNT, published data only for cancer-related mortality, and their authors did not make data on cancer occurrence available to Bangalore and others. ${ }^{4}$ One trial, Val-HeFT, was included only in the analysis of ACE inhibitor and ARB combination therapy by Bangalore and others. ${ }^{4}$ The last 2 trials, ACTIVE-I and NAVIGATOR, were published beyond the search period used by Bangalore and others. ${ }^{4}$ Conversely, Bangalore and others ${ }^{4}$ included 7 RCTs that were not included in the ATC analysis. ${ }^{3}$ The reasons for exclusion of these trials from the ATC analysis cannot be determined, as the detailed search methodology used by the ATC is not described in the published meta-analysis. ${ }^{3}$

Bangalore and others ${ }^{4}$ contacted the authors of RCTs from published ARB trials in cases where cancer data did not appear in the published reports. Additionally, Bangalore and others ${ }^{4}$ hand-searched the FDA dockets. This hand-searching may have uncovered more cancer data than the search of the FDA database performed by Sipahi and others. ${ }^{2}$ Regardless, Figure 2 shows that the additional RCTs included by both $\mathrm{ATC}^{3}$ and Bangalore ${ }^{4}$ negate the effect of ARBs on cancer occurrence relative to the original analysis by Sipahi and others. ${ }^{2}$ Additionally, if one considers the trials included by Bangalore and others $^{4}$ but not by Sipahi and others ${ }^{2}$ or the ATC, ${ }^{3}$ there is no increase in the incidence of cancer in the ARB treatment group (Figure 2).

There is one additional discrepancy between the analysis by Bangalore and others ${ }^{4}$ and those of Sipahi and others ${ }^{2}$ and the ATC. ${ }^{3}$ For the ONTARGET study, Sipahi and others ${ }^{2}$ and the $\mathrm{ATC}^{3}$ combined data for telmisartan monotherapy and
ACE inhibitor combination therapy for comparison with the placebo group, whereas Bangalore and others ${ }^{4}$ compared the telmisartan group with the placebo group and then compared the telmisartan group with the combination of ACE inhibitor and telmisartan. This double-counting of data for patients who received telmisartan in the meta-analysis by Bangalore and others $^{4}$ is not an appropriate method for combining patient outcome data. Therefore, in Figure 2, the data for ONTARGET are taken from the analysis by Sipahi and others. ${ }^{2}$

\section{DISCUSSION}

The analysis presented above indicates that the differences in the results of the 3 meta-analyses for cancer incidence in relation to ARB therapy ${ }^{1-3}$ were due to technical differences in search strategies and outcome reporting bias. This review focuses on the issue of outcome reporting bias, a problem that occurs when outcomes measured in a clinical trial are not published, in some form, upon completion of the trial. ${ }^{19,20}$ The existence of outcome reporting bias prevents us from simply classifying clinical trials as published or unpublished; because of this bias, various degrees of publication exist. Authors and clinicians are at risk of drawing spurious conclusions if they include only published outcomes in their own subsequent analyses. ${ }^{21}$ To put the prevalence of outcome reporting bias into context, one comparison of trial publications with their respective study protocols showed that, of the outcomes listed in the study protocol, only $50 \%$ had been reported in the final publication. ${ }^{21}$

A recent example of outcome reporting bias masked the apparent risk of rosiglitazone in relation to the incidence of myocardial infarction, leading to continued use of a harmful medication. GlaxoSmithKline completed a meta-analysis of 42 trials in 2005, which included previously unpublished trials and unreported cardiovascular outcomes from published trials. ${ }^{22}$ The meta-analysis demonstrated a $31 \%$ relative increase in myocardial infarction in the rosiglitazone treatment group. ${ }^{22}$ The results of this meta-analysis were not published by the drug company. Only after a lawsuit by the New York Attorney General did GlaxoSmithKline agree (in a settlement) to establish a "clinical trial registry" that would present the outcomes from all clinical trials in the public domain. Shortly thereafter, in 2007, an independent meta-analysis by Nissen and Wolski, ${ }^{23}$ which included the additional trial data from the registry, confirmed the $30 \%$ relative increase in the incidence of myocardial infarction in the rosiglitazone treatment group. This effect was replicated in 2 subsequent independent metaanalyses and an FDA review. ${ }^{22}$

Despite the availability of data for 134000 patients, outcome reporting bias in ARB trials has made it very difficult to determine the true effect of ARBs on the incidence of cancer. ${ }^{2-5}$ Of the original 15 published RCTs included in the ATC 
analysis, ${ }^{3}$ the published manuscripts for 10 RCTs did not report on the incidence of cancer. Sipahi and others ${ }^{2}$ not only searched public databases but also contacted the primary authors of the VALUE trial to gather cancer outcomes in the ARB treatment group, in an effort to avoid reporting bias in their metaanalysis (Ilke Sipahi, personal communication, September 2011). The authors of VALUE did not provide the requested data to the Sipahi team but did provide the requested data for the ATC meta-analysis, ${ }^{3}$ in which they participated. Once these data were included in the analysis, the effect of ARB on risk of cancer was negated. ${ }^{3}$ The outcome data used in the ATC analysis are privately owned and not available upon request. They exist in the public domain only as partially verifiable data within the ATC analysis ${ }^{3}$ that serve to negate the negative effects demonstrated by Sipahi and others. ${ }^{2}$ However, they ought to exist as raw patient-level data available for independent analysis, so that the true effect of ARBs on the incidence of cancer can be verified by independent analysis.

Bangalore and others ${ }^{4}$ completed their analysis after Sipahi and others ${ }^{3}$ and before publication of the ATC analysis. ${ }^{3}$ By contacting the authors of certain RCTs who were involved in the ATC analysis, the Bangalore team was able to obtain unpublished outcome data for some but not all of the RCTs included in the ATC analysis. This may have been due to the timing of their request for additional data, as the ATC analysis was under way, and perhaps the outcome data included in the latter analysis were more readily available to be shared. Regardless, despite contacting authors directly, Bangalore and others ${ }^{4}$ were unsuccessful in obtaining outcome data for all of the clinical trials that were included in the ATC analysis. ${ }^{3}$

The subsequent FDA analysis ${ }^{5}$ included more trials, with cancer outcome data from just under 156000 patients. It confirmed the finding of no difference in cancer incidence between the ARB treatment group and the control group. Despite a freedom-of-information request submitted to the FDA, the patient-level data included in the analysis are not accessible in the public domain (FDA Division of Drug Information, communication by email, September 2011). The FDA is an independent health care regulatory organization representing an impartial source of drug information, and clinicians inherently trust the agency's reports. However, it is disconcerting that the FDA does not openly share data within the public domain in a form that would facilitate independent analysis.

This review has exemplified the perils of outcome reporting bias and how it erodes the utility of meta-analysis as a tool for scientific inquiry. ${ }^{24,25}$ Meta-analysis, which involves pooling data from a collection of clinical trials, allows appreciation of small, yet significant, differences between interventions that would otherwise be overlooked. ${ }^{26}$ In the presence of outcome reporting bias, the analysis of data available in the public domain may not be representative of the true effect of an intervention on a particular outcome. ${ }^{26}$ Without public access to all outcome data collected during clinical trials, independent review and verification of clinical outcomes are impossible. There is potential for health care regulators, such as Health Canada and the FDA, to play a role in preserving the value of the systematic review and meta-analysis process by mandating that all outcome data collected in clinical trials performed on human subjects be published, in some form, within the public domain. If this measure were taken, outcome reporting bias would be eliminated.

\section{CONCLUSIONS}

Among clinicians, the prevalence of outcome reporting bias is largely underappreciated, and health care regulators currently have no mechanism in place to mitigate the possibility of outcome reporting bias. When independent researchers complete a seemingly comprehensive review of a clinical question, the possibility of outcome reporting bias means that they may not have access to all of the patient-level data that have been collected during clinical trials. For front-line clinicians, it is prudent to consider the possibility of outcome reporting bias when interpreting the results of systematic reviews and meta-analyses. The 3 meta-analyses considered here ${ }^{2-4}$ asked comparable clinical questions and undertook similar search strategies but identified different sets of RCT outcome data for inclusion in their respective analyses. To discern the subtle reasons for the different subsets of data included in each analysis takes much more time and energy than most clinicians are able to expend.

This case study serves as a pointed example of how outcome reporting bias can affect the results of a meta-analysis. Despite our own requests for patient-level data from the ATC and the FDA, we, as a group of independent researchers, were unable to obtain these data. Ultimately, it should be the responsibility of health care regulators to eliminate outcome reporting bias in RCTs by mandating the publication of all patient-level data collected in clinical trials. Until that time, researchers and clinicians who are interpreting the results of systematic reviews and meta-analyses should consider the potential of outcome reporting bias and how it might affect the outcome of the analysis.

\section{References}

1. Pfeffer MA, Swedberg K, Granger CB, Held P, McMurray JJV, Michelson EL, et al.; CHARM Investigators and Committees. Effects of candesartan on mortality and morbidity in patients with chronic heart failure: the CHARM-Overall programme. Lancet 2003;362(9386):759-766.

2. Sipahi I, Debanne SM, Rowland DY, Simon DI, Fang JC. Angiotensinreceptor blockade and risk of cancer: meta-analysis of randomised controlled trials. Lancet Oncol 2010;11(7):627-636. 
3. ARB Trialists Collaboration. Effects of telmisartan, irbesartan, valsartan, candesartan, and losartan on cancers in 15 trials enrolling 138,769 individuals. J Hypertens 2011;29(4):623-635.

4. Bangalore S, Kumar S, Kjeldsen SE, Makani H, Grossman E, Wetterslev $\mathrm{J}$, et al. Antihypertensive drugs and risk of cancer: network meta-analyses and trial sequential analyses of 324,168 participants from randomised trials. Lancet Oncol 2011;12(1):65-82.

5. FDA drug safety communication: No increase in risk of cancer with certain blood pressure drugs—angiotensin receptor blockers (ARBs). Silver Spring (MD): US Food and Drug Administration; 2011 June 2 [cited 2011 Oct 22]. Available from: www.fda.gov/Drugs/DrugSafety/ ucm257516.htm\#healthcare

6. Olin J, Veverka A, Nuzum DS. Risk of cancer associated with the use of angiotensin II-receptor blockers. Am J Health Syst Pharm 2011;68(22): 2139-2146.

7. Taylor AA, Siragy H, Nesbitt S. Angiotensin receptor blockers: pharmacology, efficacy, and safety. J Clin Hypertens (Greenwich) 2011;13(9): 677-686.

8. Willis LM, El-Remessy AB, Somanath PR, Deremer DL, Fagan SC. Angiotensin receptor blockers and angiogenesis: clinical and experimental evidence. Clin Sci (Lond.) 2011;120(8):307-319.

9. Uemura $H$, Ishiguro $H$, Nagashima $Y$, Sasaki T, Nakaigawa N, Hasumi $H$, et al. Antiproliferative activity of angiotensin II receptor blocker through cross-talk between stromal and epithelial prostate cancer cells. Mol Cancer Ther 2005;4(11):1699-1709.

10. Böhm M, Laufs U, Pfreundschuh M. Angiotensin-receptor blockade, cancer, and concerns. Lancet Oncol 2010;11(9):818-819; author reply 821-822.

11. Dicpinigaitis PV. Angiotensin-converting enzyme inhibitor-induced cough: ACCP evidence-based clinical practice guidelines. Chest 2006;129(1 Suppl):169S-173S.

12. Arnold JMO, Liu P, Demers C, Dorian P, Giannetti N, Haddad H, et al. Canadian Cardiovascular Society consensus conference recommendations on heart failure 2006: diagnosis and management. Can J Cardiol 2006;22(1):23-45.

13. Cheung BMY, Cheung GTY, Lauder IJ, Lau CP, Kumana CR. Metaanalysis of large outcome trials of angiotensin receptor blockers in hypertension. J Hum Hypertens 2006;20(1):37-43.

14. Heran BS, Wong MMY, Heran IK, Wright JM. Blood pressure lowering efficacy of angiotensin receptor blockers for primary hypertension. Cochrane Database Syst Rev 2008;(4):CD003822.

15. Strippoli GFM, Craig M, Deeks JJ, Schena FP, Craig JC. Effects of angiotensin converting enzyme inhibitors and angiotensin II receptor antagonists on mortality and renal outcomes in diabetic nephropathy: systematic review. BMJ Clin Res Ed 2004;329(7470):828.

16. Epstein BJ, Gums JG. Angiotensin receptor blockers versus ACE inhibitors: prevention of death and myocardial infarction in high-risk populations. Ann Pharmacother 2005;39(3):470-480.

17. Shibata MC, Tsuyuki RT, Wiebe N. The effects of angiotensin receptor blockers on mortality and morbidity in heart failure: a systematic review. Int J Clin Pract 2008;62(9):1397-1402.
18. Jong P, Demers C, McKelvie RS, Liu PP. Angiotensin receptor blockers in heart failure: meta-analysis of randomized controlled trials. J Am Coll Cardiol 2002;39(3):463-470.

19. Dwan K, Altman DG, Arnaiz JA, Bloom J, Chan AW, Cronin E, et al. Systematic review of the empirical evidence of study publication bias and outcome reporting bias. PloS One 2008;3(8):e3081.

20. Young NS, Ioannidis JPA, Al-Ubaydli O. Why current publication practices may distort science. PLoS Med 2008;5(10):e201.

21. McGauran N, Wieseler B, Kreis J, Schüler YB, Kölsch H, Kaiser T. Reporting bias in medical research—a narrative review. Trials 2010;11:37.

22. Nissen S, Califf R. A conversation about rosiglitazone. In: Medscape diabetes endocrinology. WebMD LLC; 2007 [cited 2012 Feb 15]. Available from: www.medscape.com/viewarticle/561666. Registration required to access content.

23. Nissen SE, Wolski K. Effect of rosiglitazone on the risk of myocardial infarction and death from cardiovascular causes. $N$ Engl J Med 2007; 356(24):2457-2471.

24. Egger M, Smith GD. Bias in location and selection of studies. BMJ 1998;316(7124):61.

25. Schell CL. Metamanalysis: a tool for medical and scientific discoveries. Bull Med Libr Assoc 1992;80(3):219-222.

26. Blood pressure pills linked to cancer. CBC News Health 2010 Jun 14 [cited 2011 Oct 20]. Available from: www.cbc.ca/news/health/story/ 2010/06/14/blood-pressure-cancer.html

Gregory Egan, BSc(Pharm), is with the Pharmacy Department, Royal Columbian Hospital, New Westminster, British Columbia.

Jana Lee, BSc(Pharm), is with the Pharmacy Department, Royal Columbian Hospital, New Westminster, British Columbia.

Rajwant Minhas, BSc(Pharm), is with the Pharmacy Department, Langley Memorial Hospital, Langley, British Columbia.

Aaron M Tejani, BSC(Pharm), PharmD, ACPR, is with the Pharmacy Department, Burnaby Hospital-Fraser Health Authority, Burnaby, British Columbia.

\section{Address correspondence to:}

Gregory Egan

Pharmacy

Royal Columbian Hospital

330 East Columbia Street

New Westminster BC V3L 2W7

e-mail: gregory.egan@fraserhealth.ca 